\title{
Pediatrik Vasküler Erişim Uygulamalarında Güncel Yaklaşım: Damar Görüntüleme Tekniği
}

\author{
Yağmur Şanci'®D, Serap Balcı² ${ }^{2}$
}

${ }^{1}$ Acıbadem Mehmet Ali Aydınlar Üniversitesi, Hemşirelik Bölümü, İstanbul, Türkiye

2̇̇stanbul Üniversitesi-Cerrahpaşa, Florence Nightingale Hemşirelik Fakültesi, İstanbul, Türkiye

Yağmur Şancı, Uzm. Hemş. Serap Balcı, Doç. Dr.

Illetişim:

Uzm. Hemş. Yağmur Şancı

Acıbadem Mehmet Ali Aydınlar Üniversitesi, Hemşirelik Bölümü, İstanbul, Türkiye Tel: +902165004170

E-Posta:yagmursanc@gmail.com
Gönderilme Tarihi : 22 0cak 2018

Revizyon Tarihi : 30 Mayıs 2018

Kabul Tarihi : 01 Haziran 2018

\section{ÖZET}

Çocukluk çağında damar çaplarının küçüklüğü, damar yapılarının tam gelişmemiş olması gibi nedenlerden dolayı periferik intravenöz katater uygulamaları erişkin hastalara göre teknik olarak daha güçtür. Bu nedenle, intravenöz uygulamalar sırasında oluşabilecek ağrının önlenmesi veya en aza indirgenmesi için çocukluk dönemi vasküler erişim uygulamalarında atravmatik bakım uygulanmalıdır. Atravmatik bakımın temel ilkelerinden biri olan bedensel yaralanmayı ve ağrıyı en aza indirmek veya önlemek ilkesi doğrultusunda; vasküler erişim uygulamalarında işlemin başarısını arttıracak, işlemin süresini kısaltacak ve ağrıyı azaltacak teknolojilerin kullanması önerilmektedir. Bu teknolojilerden biri olan damar görüntüleme tekniğinin; işlemin süresini kısalttığı, sağlık personelinin iş gücünü azalttığı, başarılı vasküler erişime bağlı olarak ağrıya maruziyeti azalttığı, çocuğun ve ailenin stresini azaltarak atravmatik bakım ilkelerine dayalı girişime olanak sağladığı gözlenmektedir.

Anahtar sözcükler: Vasküler erişim, pediatri, damar görüntüleme, ağrı, atravmatik bakım

CURRENT APPROACH TO PEDIATRIC VASCULAR ACCESS APPLICATIONS: VESSEL VISUALIZATION TECHNIQUE

\section{ABSTRACT}

Peripheral intravenous catheterization is technically more difficult in pediatric patients than adult patients due to some/many reasons such as small vessel diameters during childhood and insufficiency of vascular structures. For this reason, atraumatic care should be applied to childhood vascular access practices to prevent or minimize pain during intravenous administration. One of the basic principles of atraumatic care is to reduce or prevent bodily injury and pain; it is recommended to use technologies that will shorten the duration of the procedure and reduce pain in vascular access applications. One of these technologies is the vascular imaging technique. It is observed that this technology reduced the health personnel workload, reduced the pain exposure due to a successful vascular access, reduced the stress of the child and the family and enabled the intervention based on the atraumatic care principles.

Keywords: Vascular access, pediatrics, vascular imaging, pain, atraumatic care

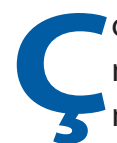
ocukluk çağında damar çaplarının küçüklüğü, damar yapılarının tam gelişmemiş olması gibi nedenlerden dolayı Periferik Intravenöz Kateter (PIK) uygulamaları erişkin hastalara göre teknik olarak daha güçtür. İntravenöz (IV) girişimlerin bebek ve çocuklarda travmatik, ağrılı, korku verici ve anksiyete oluşturabilecek nitelikte olduğu bilinmektedir (1). Ayrıca, literatürde bebek ve çocukların yaşadığı ağrının ebeveynlerde de psikolojik strese neden olduğu bildirilmiştir $(2,3,4)$. Doğru kateter uygulamasının, tedaviye gelen çocuğun ve ailesinin zor damar yolu bulmanın yarattığı stresten kurtardığı, günlük hayatlarının kalitesini arttırdığı ve ailenin verilen 
tıbbi bakıma güvenini arttırdığı gösterilmiştir (5). Bu nedenlerden dolayı, IV uygulamalar sırasında oluşabilecek ağrının önlenmesi veya en aza indirgenmesi için çocukluk dönemi vasküler erişim uygulamalarında atravmatik bakım yöntemleri uygulanmalıdır (6).

Çocukluk çağının akut ve kronik hastalıklarında sıvı ve elektrolit kaybının yerine konulması, kan veya elemanlarının verilmesi, asit-baz dengesinin düzenlenmesi ve acil tedavinin verilmesi için vasküler erişim gereklidir. Tedavinin etkin bir şekilde uygulanması açısından oldukça önemli olan bu girişim PIK yerleştirilerek gerçekleştirilmektedir. Erişkin ve pediatrik vasküler erişim literatürünün çoğu, IV girişim tekniklerine, komplikasyonlara veya işlem sırasında ağrıyı azaltma tekniklerine odaklanmıştır $(3,7,8,9,10,11,12)$.

IV girişimin başarısl; damar problemlerine, hipovolemi durumuna, periferal ödem varlığına, kullanılacak araç gereçlerin nitelik ve niceliğine, ortamın stres düzeyinin yüksekliğine bağlı olarak değişmektedir. Black ve arkadaşlarının (2005) yaptığı çalışmada, hemşirenin deneyim yıllarının IV girişim başarısı ile anlamlı bir ilişki göstermediği belirtilmiştir (9). Pediatrik intravenöz girişimlerde, teknik olarak amaç ilk girişimde başarı olmasına rağmen, Tablo 1'de de görüldüğü üzere pediatri kliniklerinde ilk girişimde başarı oranı düşüktür. Larsen ve arkadaşlarının (2010) çalışmasında ilk IV girişimin başarı oranı \%46 olarak belirtilmiştir (8). Jacobson ve Winslow'un çalışmasında 34 hemşire tarafından uygulanan 339 IV girişimin \%77'sinin başarılı olduğu, bunlardan \%65'inin ilk deneyimde başarıya ulaştığı gözlenmiştir (13). IV uzman ekibinin ise PIK yerleştirmede çok başarılı olduğu ve 430 girişimin \%91'inin ilk denemede yerleştirildiği belirlenmiştir (14). Çocuk hastanesinde yapılan prospektif bir çalışmada, hemşirelerin başarılı bir PiK yerleştirmek için gerekli olan girişim sayısı incelenmiş ve pediatride PIK yerleştirmek için ortalama 2,35 girişimin yapıldığı saptanmıştır. İlk denemede \%53'ünün başarılı olduğu, dördüncü deneme sonucunda \%91 başarıya ulaşıldığı belirtilmiştir (15). Benzer bir çalışmada, acil servis hemşirelerinin PIK uygulamasında ilk denemede \%75 oranında başarı gösterdiği belirtilmiştir (3). Goff ve arkadaşlarının 2013 yılında yaptığı çalışmada 592 yatan çocuk hasta ele alınmıştır ve bu çocuklara uygulanan ilk ya da ikinci IV girişimde başarı oranı \%72 olarak bulunmuştur (Tablo 1) (16).

The use of near-infrared light for safe and effective visualization of subsurface blood vessels to facilitate blood withdrawal in children. Medical engineering \& physics, 35(4), 433-440' tan uyarlanmıştır (17).

Atravmatik bakımın temel ilkelerinden biri olan bedensel yaralanmayı ve ağrıyı en aza indirmek veya önlemek ilkesi

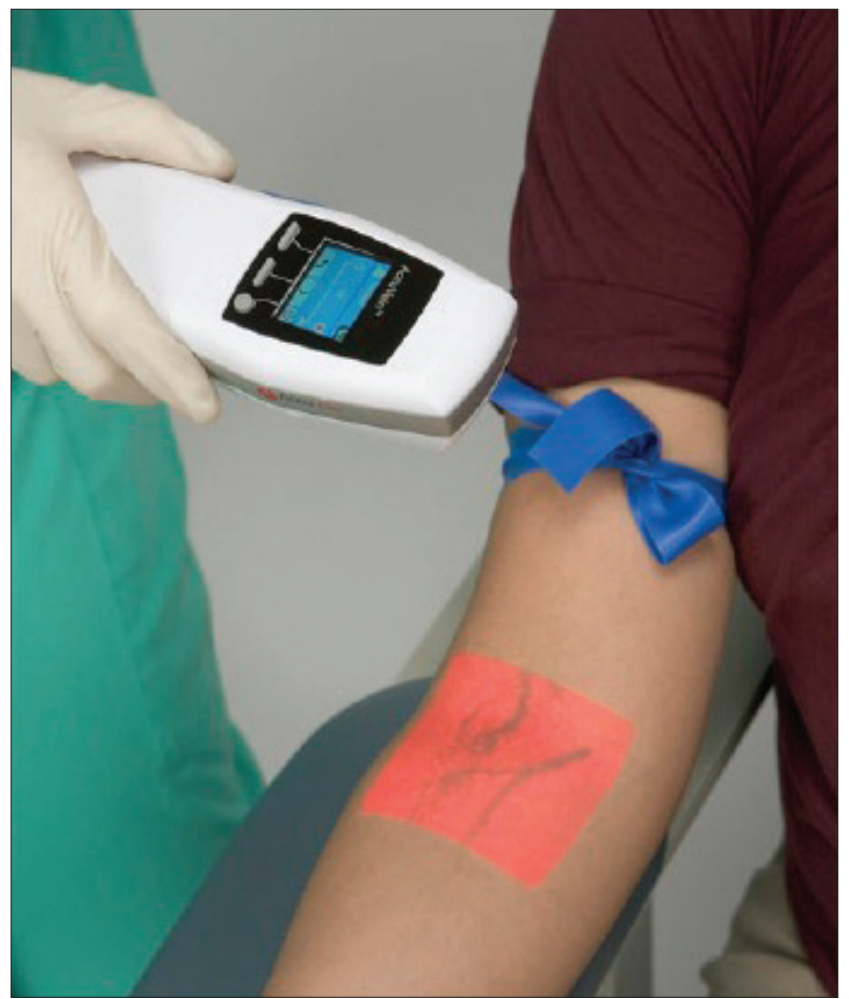

Şekil 1. Kızıötesi damar görüntüleme (22)

doğrultusunda; vasküler erişim uygulamalarında işlemin başarısını arttıracak, işlemin süresini kısaltacak ve ağrıyı azaltacak teknolojilerin kullanması önerilmektedir (18). Bu gibi problemlerin olası bir çözümü olarak damar görüntüleme cihazı gibi, deri yüzeyi altındaki kan damarlarının görselleştirilmesi ile lokalizasyonun geliştirilmesi teknolojisi kullanılmaya başlanmıştır. Vasküler Erişim uygulamalarında hasta açısından daha az acılı bir şekilde gerçekleştirilmesini sağlayacak olan damar görüntüleme cihazı, hastanın ve sağlık görevlisinin fiziksel ve ruhsal yükünü azaltmaktadır. Bu sayede hasta üzerinde uygulanacak diğer bütün işlemler daha hızlı ve sağlıklı bir şekilde gerçekleştirilmektedir (19). Damar görüntülemede kullanılan çeşitli yöntemler vardır. Ultrason, damar görüntülemede kullanılan yöntemlerden birisidir. Geleneksel vasküler erişim uygulamalarına göre etkinliği kanıtlanmıştır (20). Ancak ekstra beceri ve yardım gerektirir, maliyeti de yüksektir (21). Damar görüntülemede diğer bir yöntem ise kızılötesi ışık kaynağı kullanarak damar harita yapılarının tespit edilmesidir (19).

Literatürde kızı̈ötesi damar görüntüleme cihazı destekli vasküler erişim uygulamalarına yönelik sınırlı çalışma bulunmaktadır $(1,18,22,23,24,25,26)$. Hess'in (2010) çalışmasında 0-17 yaş pediatri hastalarında damar görüntüleme cihazının kullanılmasının, ilk vasküler erişim başarı oranını \%40.3'ten \%80.2'ye arttırdığı, hasta başına deneme sayısını 
azalttığı ve çalışma popülasyonu için işlem süresini azalttığı belirtilmiştir (1). Guillon ve arkadaşlarının (2015) 165 hasta üzerinde yaptığı çalışmada, damar görüntüleme tekniğinin hemofili tanılı zor damar erişimine sahip hastalarda işlem başarısını arttırdığı ve ağrıyı azalttığı belirtilmiştir (Şekil 1) (22). Demir'in (2015) 129 pediatri hastasında Accuvein damar görüntüleme cihazı destekli periferik intravenöz kateter yerleştirmenin işlem başarısına etkisinin belirlenmesi amacıyla yaptığı çalışmasında, işlem başarısının arttırtığı, işlem süresinin kısaldığı ve işlem sırasında hissedilen ağrıyı azalttığı saptanmıştır (18). Bir başka çalışma 1-10 yaş arası kontrol gruplu 110 çocukta ven görüntüleme cihazının ilk girişimde başarısına bakılmış ve girişim sayısının daha az olduğu, işlem süresinin azaldığı, ilk girişimde başarı oranının arttığı belirtilmiştir (23). Çağlar ve arkadaşlarının (2017) yaptığı çalışmada preterm bebeklerde periferik intravenöz kateter yerleştirme sırasında kullanılan infrared (Accuvein AV400) ve transluminatör (Wee Sight) ışık kaynaklı iki farkIı damar görüntüleme cihazının etkinliği karşılaştııımış ve pretermlerde periferik intravenöz kateter girişimi sırasında infrared ışık kaynağı teknolojisi (Accuvein AV400) kullanımının; ağrı skoru, kateter girişim süresi, ilk denemede yerleştirme başarısı, kalış süresi üzerinde etkili ve güvenilir olduğu görülmüştür (24). Çocuklarda periferal kanül uygulaması

Tablo 1. Literatürde yer alan vasküler erişim başarı oranları

\begin{tabular}{|c|c|c|c|c|c|}
\hline Yayın & Yer & Grup & $\begin{array}{l}\text { IIlk girişimde } \\
\text { başarı oranı }\end{array}$ & $\begin{array}{c}\text { Kanülüzasyon } \\
\text { başarı oranı }\end{array}$ & $\begin{array}{c}\text { Hasta-Girişim } \\
\text { sayısı }\end{array}$ \\
\hline \multirow[t]{4}{*}{ Tsai, 1987} & \multirow{4}{*}{$\begin{array}{l}\text { Hastane öncesi, ilk } \\
\text { yardım uygulaması }\end{array}$} & Bebek & & $\% 28.6$ & 7 \\
\hline & & Okul öncesi & & $\% 65.5$ & 29 \\
\hline & & Okul çocuğu & & $\% 84.5$ & 58 \\
\hline & & Adölesan & & $\% 92.2$ & 348 \\
\hline Lillis, 1992 & $\begin{array}{l}\text { Hastane öncesi, ilk } \\
\text { yardım uygulaması }\end{array}$ & & $\% 71$ & $\% 84$ & 300 \\
\hline \multirow[t]{2}{*}{ Friedland, 1992} & \multirow[t]{2}{*}{ Çocuk hastanesi } & $\begin{array}{c}\text { Emniyet mekanizmalı } \\
\text { IV katater kullanımından önce }\end{array}$ & $\% 74$ & & 214 \\
\hline & & $\begin{array}{c}\text { Emniyet mekanizmalı } \\
\text { IV katater kullanımından sonra }\end{array}$ & $\% 86$ & & 35 \\
\hline \multirow[t]{2}{*}{ Choudhry, 1998} & \multirow[t]{2}{*}{ Cerrahi servisi } & $\begin{array}{l}\text { Anestezi sırasında erken } \\
\text { kanülüzasyon uygulanan }\end{array}$ & $\% 68$ & & 78 \\
\hline & & $\begin{array}{l}\text { Anestezi sırasında geç } \\
\text { kanülüzasyon uygulanan }\end{array}$ & $\% 74$ & & 72 \\
\hline \multirow[t]{3}{*}{ Frey, 1998} & \multirow[t]{3}{*}{ Çocuk hastanesi } & Hemşire & & $\% 44$ & 197 \\
\hline & & Doktor & & $\% 23$ & 416 \\
\hline & & IV Team Hemşiresi & & $\% 98$ & 43 \\
\hline Lininger, 2003 & Çocuk hastanesi & & $\% 53$ & & 249 \\
\hline \multirow[t]{2}{*}{ Black, 2005} & Acil & $\begin{array}{c}\text { Kataterin keskin ucunu } \\
\text { yukarı göstererek uygulama }\end{array}$ & $\% 75.6$ & & 201 \\
\hline & & $\begin{array}{l}\text { Kataterin keskin ucunu } \\
\text { aşağı göstererek uygulama }\end{array}$ & $\% 60.0$ & & 195 \\
\hline \multirow[t]{2}{*}{ Taddio, 2005} & Acil & Lidokain & $\% 74$ & & 69 \\
\hline & & Plesebo & $\% 55$ & & 73 \\
\hline Costantino, 2005 & Üniversite hastanesi & IV Team Hemşiresi & $\% 91$ & & 430 \\
\hline Jacobson, 2005 & Hastane & Hemşire & $\% 65$ & $\% 77$ & 339 \\
\hline Yen 2008 & Acil & & $\% 75$ & $\% 86$ & 615 \\
\hline Arendts, 2008 & Acil & & $\% 75$ & & 177 \\
\hline \multirow[t]{4}{*}{ Larsen, 2010} & Çocuk hastanesi & Deneyim < 1yıl & $\% 34$ & & 592 \\
\hline & & $1-3 \mathrm{yll}$ & $\% 31$ & & \\
\hline & & $3-5 \mathrm{yll}$ & $\% 12$ & & \\
\hline & & $>5 \mathrm{yll}$ & $\% 23$ & & \\
\hline \multirow[t]{2}{*}{ Nafliu, 2010} & Cerrahi servisi & Zayıf & $\% 59.2$ & & 56 \\
\hline & & Obez & $\% 40.8$ & & 47 \\
\hline \multirow[t]{2}{*}{ Hess, 2010} & Çocuk servisi & Geleneksel yol ile & $\% 49.3$ & & 150 \\
\hline & & Damar Görüntüleme Cihazı ile & $\% 80.2$ & & 91 \\
\hline Goff, 2013 & Çocuk hastanesi & Cerrahide yatan hastalar & & $\% 72$ & 592 \\
\hline Guillon, 2015 & Üniversite hastanesi & Hemofili tanılı hastalar & $\% 75.2$ & & 165 \\
\hline
\end{tabular}


sırasında kullanılan damar görüntülemenin ağrı ve anksiyete üzerine etkisinin araştııılığı bir çalışmada, periferal kanül uygulaması esnasında ağrı ve anksiyete yaşayan çocuklarda damar görüntüleme cihazı kullanımının, ağrı ve anksiyeteyi azalttığı, girişim süresini kısalttığı belirlenmiştir (25). Ven görüntüleme cihazı destekli damar yolu açmanın 0-3 yaş arası çocuklarda işlem başarısı ve ağrı düzeyine etkisinin incelendiği çalışmada, hasta başına düşen girişim sayısını ve girişim süresini azalttığı, ilk girişimde başarı hızını arttırdığı, ayrıca işlemin daha az ağrı ile gerçekleştirilmesini sağladığı saptanmıştır (26).

\section{Kaynaklar}

1. Hess, H. A. A biomedical device to improve pediatric vascular access success. Pediatric nursing, 2010;36:259-63.

2. Smith RW., Shah V., Goldman RD., Taddio A. Caregivers' responses to pain in their children in the emergency department. Archives of pediatrics \& adolescent medicine, 2007; 161:578-82. [CrossRef]

3. Yen K., Riegert A., Gorelick, MH. Derivation of the DIVA score: a clinical prediction rule for the identification of children with difficult intravenous access. Pediatric emergency care, 2008; 24:143-7. [CrossRef]

4. Gerçeker, GÖ., Gümüş M., Yardımcı F., Polat ME., Eroğlu, B., İslamoğlu A. Çocuklar İçin Zorlu İntravenöz Girişim Skorunun Türkçe Versiyonunun Psikometrik Özellikleri. Dokuz Eylül Üniversitesi Hemşirelik Fakültesi Elektronik Dergisi, 2017; 10:153-8.

5. Tremolada M., Axia V., Pillon M., Scrimin S., Capello F., Zanesco L. Parental narratives of quality of life in children with leukemia as associated with the placement of a central venous catheter. J Pain Symptom Manage 2005; 30:544-52. [CrossRef]

6. Pazarcıkcı F, Efe E. Çocukluk Dönemi Aşı Uygulamalarında Atravmatik Bakım Yöntemleri. Uluslararası Hakemli Kadın Hastalıkları ve Anne Çocuk Sağlığı Dergisi. 2017; 9: 62-77.

7. Kuş B., Büyükyılmaz F. Periferik Intravenöz Kateter Uygulamalarında Komplikasyonların Önlenmesinde Güncel Kanıtlar: Sistematik İnceleme. Florence Nightingale Hemşirelik Dergisi, 2017; 25:209-17. [CrossRef]

8. Larsen P., Eldridge D., Brinkley J., Newton D., Goff D., Hartzog T., et al. Pediatric peripheral intravenous access: does nursing experience and competence really make a difference?. J Infus Nurs, 2010;33:22635. [CrossRef]

9. Black KJ., Pusic MV., Harmidy D., McGillivray D. Pediatric intravenous insertion in the emergency department: bevel up or bevel down?. Pediatr Emerg Care, 2005; 21:707-11.

10. Stevenson MD., Bivins CM., O’Brien K., Gonzalez del Rey JA. Child life intervention during angiocatheter insertion in the pediatric emergency department. Pediatr Emerg Care, 2005; 21:712-8.

11. Singer AJ., Taira BR., Chisena EN., Gupta N., Chipley J. Warm lidocaine/tetracaine patch versus placebo before pediatric intravenous cannulation: a randomized controlled trial. Ann Emerg Med 2008;52:41-47. [CrossRef]

12. Zempsky WT. Optimizing the management of peripheral venous access pain in children: evidence, impact, and implementation. Pediatrics 2008; 122(Suppl 3):121-4. [CrossRef]

13. Jacobson AF., Winslow EH. Variables influencing intravenous catheter insertion difficulty and failure: an analysis of 339 intravenous catheter insertions. Heart \& Lung 2005; 34:345-59. [CrossRef]

14. Costantino TG., Parikh AK., Satz WA., Fojtik JP. Ultrasonographyguided peripheral intravenous access versus traditional approaches in patients with difficult intravenous access. Ann Emerg Med 2005;46:456-61. [CrossRef]

\section{Sonuç}

Yapılmış tüm çalışmaların sonuçları temel alınarak damar görüntüleme tekniğinin; işlemin süresini kısalttığı, sağlık personelinin iş gücünü azalttığı, başarılı vasküler erişime bağlı olarak ağrıya maruziyeti azalttığı, çocuğun ve ailenin stresini azaltarak atravmatik bakım ilkelerine dayalı girişime olanak sağladığı gözlenmektedir. Pediatri servislerinde çalışan hemşirelere bu konuda bilinçlendirme sağlanması ve çocuk servislerinin bağlı olduğu kurumların bu teknolojileri kullanılmasına yönelik teşvik edilmesi gerekmektedir.

15. Lininger RA. Pediatric peripheral IV insertion success rates. Pediatr Nurs 2003; 29:351-4.

16. Goff DA., Larsen P., Brinkley J., Eldridge D., Newton D., Hartzog T., et al. Resource utilization and cost of inserting peripheral intravenous catheters in hospitalized children. Hosp Pediatr. 2013; 3:185-91.

17. Cuper NJ., Klaessens JH., Jaspers JE., de Roode R., Noordmans HJ., de Graaff JC., et al. The use of near-infrared light for safe and effective visualization of subsurface blood vessels to facilitate blood withdrawal in children. Med Eng Phys. 2012;35:433-40. [CrossRef]

18. Demir D., İnal S. Pediatri hastalarında accuvein damar görüntüleme cihazı destekli periferik intravenöz kateter yerleştirmenin işlem başarısına etkisi. Yayınlanmamış Yükseklisans Tezi. Haliç Üniversitesi. Sağlık Bilimleri Enstitüsü. İstanbul (2015).

19. Boyraz ÖF., Yildiz MZ. Mobil Damar Görüntüleme Cihazı Tasarımı. In 4th International Symposium on Innovative Technologies in Engineering and Science (ISITES2016) 3-5 Nov 2016 Alanya/Antalya-Turkey.

20. Vinograd AM., Zorc JJ., Dean AJ., Abbadessa MK., Chen AE. FirstAttempt Success, Longevity, and Complication Rates of UltrasoundGuided Peripheral Intravenous Catheters in Children. Pediatr Emerg Care. 2018;34:376-80. [CrossRef]

21. Doniger SJ., Ishimine P., Fox JC., Kanegaye JT. Randomized controlled trial of ultrasound-guided peripheral intravenous catheter placement versus traditional techniques in difficult-access pediatric patients. Pediatr Emerg Care. 2009; 25:154-9. [CrossRef]

22. Guillon P., Makhloufi M., Baillie S., Roucoulet C., Dolimier E., Masquelier AM. Prospective evaluation of venous access difficulty and a nearinfrared vein visualizer at four French haemophilia treatment centres. Haemophilia, 2015; 21:21-6. [CrossRef]

23. Gümüş M., Başbakkal D.Z. Periferal venöz kateter uygulamasında ven görüntüleme cihazı kullanımının ilk girişimde başarı oranına etkisi. 6. Ulusal 1. Uluslararası Pediatri Hemşireliği Kongresi. Sözel Bildiri. Antalya, 29 Kasım 2017.

24. Çağlar S., Büyükyılmaz F., Bakoğlu İ., İnal S., Salihoğlu Ö. Preterm bebeklerde periferik intravenöz kateter yerleştirmede iki farklı damaryolu görüntüleme cihazının etkinliğinin karşılaştırılması: randomize kontrollü çalışma. 6. Ulusal 1. Uluslararası Pediatri Hemşireliği Kongresi. Sözel Bildiri. Antalya, 29 Kasım 2017.

25. Bayram D., Topan A. Çocuklarda periferal kanül uygulaması sırasında kullanılan damar görüntülemenin ağrı ve anksiyete üzerine etkisi. Yayınlanmamış Yüksek Lisans Tezi. Bülent Ecevit Üniversitesi.Sağlık Bilimleri Enstitüsü, Zonguldak (2016).

26. İnal S., Demir D. Ven görüntüleme cihazı destekli damar yolu açmanın 0-3 yaş çocuklarda işlem başarısı ve ağrı düzeyine etkisi. 6. Ulusal 1. Uluslararası Pediatri Hemşireliği Kongresi. Sözel Bildiri. Antalya, 1 Aralık 2017. 